\title{
Response of (Vitis vinifera L.) cv. Fantasy Seedless to water deficit treatments: Phenolic compounds and physiological activities
}

\author{
O. Soltekin ${ }^{1}$, A. Güler ${ }^{1}$, A. Candemir ${ }^{1}$, A. Altındişli ${ }^{2}$, and A. Unal ${ }^{1}$ \\ ${ }^{1}$ Manisa Viticultural Research Institute, Yunusemre, Manisa, Turkey \\ ${ }^{2}$ Ege University, Faculty of Agriculture, Department of Horticulture, Izmir, Turkey
}

\begin{abstract}
This paper describes an investigation on the effects of deficit irrigation treatments on phenolic compounds and physiological activities of Fantasy Seedless table grape variety. Research was conducted in Viticultural Research Institute of Manisa, located in Aegean Region of Turkey, during two consecutive years (2016-2017). Three irrigation treatments were assayed; namely full irrigation (T-F), deficit irrigations (T-35 and T-65). In T-F, soil water deficit in the $90 \mathrm{~cm}$ within the one week intervals was completed to the field capacity. T-35 and T-65 treatments received 35\% and 65\% of water applied to T-F. Sub-surface drip irrigation system was used in the research and soil water content was measured by MobiCheck probe while vine water status was monitored through midday leaf water potential before the irrigations. Results showed that water deficit treatments (T-35 and T-65) affected berry composition particularly individual phenolics [Gallic acid, $(+)(-)$ Catechine, (-)-Epigallocatechin gallate, (-)-Epicatechin gallate, Caftaric acid, Chlorogenic acid, Caffeic acid, p-Coumeric acid, Ferulic acid, Sinapic acid, Trans-Resveratrol, Myricetin, Quercetin hydrate, Kaempferol, Oenin Chloride, Delphinidin Chloride, Cyanidin Chloride, Malvidin Chloride] differently. The highest Catechine content in the samples was obtained from T-65, T-35 and T-F treatments, respectively. Furthermore it was determined that DI treatments did not change the Myricetin and Quercetin hydrate contents in 2017. On the other hand minimum $\Psi_{\mathrm{md}}$ value was observed from the T-35 treatment in both years. Last of all, our findings show a strong relationship between the amount of water and berry composition values especially individual phenolics which are benefical to health.
\end{abstract}

\section{Introduction}

Approximately $52 \%$ of total fresh grape production in Turkey, is carried out in Aegean Region. Manisa, Denizli and Izmir are the most popular cities in terms of grape production in this region and particularly Manisa province in the Aegean Region of Turkey, is the capital city of grape production. Almost $50 \%$ of total grape production in Turkey is processed in table grape, $39 \%$ in raisin and $11 \%$ in wine. However this important table grape production potential has not enough to move the country to the desired position in international markets. Therefore it is necessary to improve the export potential of table grapes due to only $10 \%$ of table grape production can be exported. For this purpose specific growing techniques should be applied to increase export value for table grapes.

Viticulture has important place in Turkish agricultural production but viticultural practices are faced with many problems in the process from growing to marketing period. Especially the global climate change which is becoming more and more influential in recent years, directly affects yield and quality attributes [1] indicated that climate change can have direct or indirect effects on viticulture (morphological and physiological development of vine, vine phenology, fruit quality, berry composition, yield, irrigation, fertilization, storage, marketing etc.). Also it has been reported that drought (water stress) has a great influence in the mentioned effects and it is expected that there will be significant changes especially in the physiological activities of vines, grape quality and yield values [2]. In this context it is emphasized that some adaptation strategies are needed in the growing techniques with the water scarcity as a result of climate change. Therefore water requirements of the vines need to be estimated accurately and appropriate irrigation strategies should be developed for production purposes [3]. However the question of when and how much water should be applied in vineyards is still standing.

In recent years two most common irrigation tools have used based on physiological knowledge of grapevine; regulated deficit irrigation (RDI) and partial root zone drying (PRD). In RDI water is reduced according to the phenology, improving control of vegetative vigour, optimization of fruit size and quality [4]. Specifically it has been found that RDI has a positive effect over synthesis and concentration of phenolic compounds, soluble solids and anthocyanins [5]. On the other hand in PRD, approximately half of the root system is maintained sufficiently irrigated although the other part is allowed to dry. It has been reported that PRD helps in controlling excessive vegetative growth, improves grape quality and water use efficiency. Additionally PRD did not affect leaf 
conductance and berry yield [6]. Plant water status affects berry composition, but the effects might be contrasting according to the level and the phenology when water deficit is imposed. Moreover grape varieties might have different response to water stress. Overall regulation of grapevine water deficit is a effective tool to manage the amount of secondary metabolite compounds and improve grape quality [7].

This study aimed to assess the response of (Vitis vinifera L.) cv. Fantasy Seedless table grapes to water deficit treatments in terms of phenolic compounds and physiological activities.

\section{Materials and methods}

\subsection{Experimental area}

The field experiment was conducted on 6 years old Fantasy Seedless table grape variety during the 20162017 seasons, at the experimental vineyard of Manisa Viticultural Research Institute, $38^{\circ} 37^{\prime} \mathrm{N}$ and $27^{\circ} 24^{\prime} \mathrm{E}$ altitude $43.7 \mathrm{~m}$ above sea level, in Manisa, Aegean region, Turkey [8]. The Aegean region is under Mediterranean climatic conditions; summers are hot and dry while the winters are warm and rainy. According to the longterm meteorological datas, the average annual rainfall is $685 \mathrm{~mm}$ but nearly $76 \%$ of total rainfall concentrated in period from November to March. The soil of the experimental site is classified loamy soil. Soil water content at the field capacity is $233 \mathrm{~mm}$ and available water in the upper $0.90 \mathrm{~m}$ of the soil profile depth (effective root depth) is $145 \mathrm{~mm}$.

\subsection{Methods}

In the study, three different treatments were considered; namely full irrigation (T-F), deficit irrigations (T-65 and $\mathrm{T}-35$ ). In T-F soil water deficit in the $90 \mathrm{~cm}$ within the seven day intervals was replenished to the field capacity. T-65 and T-35 treatments received $65 \%$ and $35 \%$ of water applied to T-F. In both years, irrigation treatments started when the available water decreased $50 \%$ in effective root depth $(900 \mathrm{~mm})$. In the experiment, Sub-surface drip irrigation system was used as an irrigation technique and drip laterals placed $40 \mathrm{~cm}$ below the soil surface. A single drip lateral was placed at $50 \mathrm{~cm}$ from the each vine row for all treatments and laterals with inline emitters with flow rate of $3.0 \mathrm{lth}^{-1}$ spaced at $40 \mathrm{~cm}$ intervals were used (Netafim-Comp., Manisa, Turkey).

Experimental design was randomized blocks with three replications and there were six vines in each replications. Research was carried on 6 years old Fantasy Seedless table grape variety grafted on 1103 Paulsen American rootstock. Vines were planted $2.5 \mathrm{~m}$ plant spacing and $3.0 \mathrm{~m}$ row spacing. Vines were cane-pruned and rows were oriented in North-South direction.

Soil moisture content was determined by gravimetric analysis and MobiCheck probe (AquaCheck Ins., US) simultaneously. Both measurements were done once a week before the irrigation day and so MobiCheck probe was calibrated at the end of the first year. Calibration equation for the MobiCheck Probe was; $\mathrm{Pv}=$ 1.0107 GA $+26.938\left(R^{2}=0.92^{* *}\right)$ where Pv: volumetric soil water content; GA: gravimetric analysis result. Midday leaf water potential $\left(\Psi_{\mathrm{md}}\right)$ measurements were

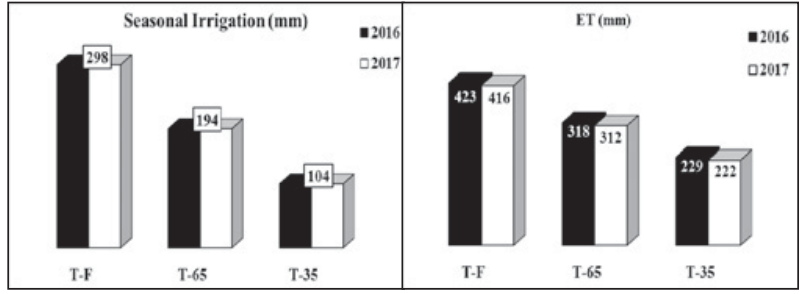

Figure 1. Seasonal irrigation quantity and Evapotranspiration values for the different treatments in both years, 2016-2017.

conducted as described by [9] $\Psi_{\mathrm{md}}$ was measured using a pressure bomb (Skye Instrument Co., UK) between 1230 and $1330 \mathrm{~h}, \mathrm{UTC}+3$ time zone. Three mature, healthy and fully expanded leaves were selected from three vines from each replicates. The leaves were selected from the middle of the canopy at the sunny side and measurements were conducted before the irrigation treatments, regularly.

At harvest, different parameters were also measured to characterize berry quality and composition. These measurements were based on cluster samples of 6 vines per replicate for each treatment. To evaluate berry composition, individual phenolics, total anthocyanins and antioxidant capacity values were determined. Individual phenolics in grape samples are determined by HPLC (Agilent 1200 infinity) technique. For this purpose, the methods of [10] and [11] were slightly modified and used in this study. Determination of phenolic compounds were carried on a ODS C18 $(250 \times 4.6 \mathrm{~mm} 5 \mu \mathrm{m})$ column using diode array detector (DAD). The column oven temperature was set at $30^{\circ} \mathrm{C}$. Flow rate was $1 \mathrm{~mL} / \mathrm{min}$, the volume of injection was $10 \mu \mathrm{L}$ and elution time was $65 \mathrm{~min}$. Measurements were set at 280, 320, 360, $520 \mathrm{~nm}$ and the elution gradient was used. Mobile phases were $0.2 \%$ formic acid and Methanol. On the other hand total anthocyanin content and antioxidant capacity were determined according to the [12] and [13], respectively.

Data were analysed statistically using SPSS Statistical software. Treatments means were compared using LSD test.

\section{Results and discussion}

\subsection{Soil-Vine water relations}

Water restriction period during the vine development is critical success of deficit irrigation treatments. In this study, when $50 \%$ of the available water is depleted at $90 \mathrm{~cm}$ soil depth, irrigation is started and continued until harvest once a week regularly. The first irrigation was applied on June 16, 2016 and June 15, 2017 and final irrigation was applied August 11, 2016 and August 10, 2017, respectively. Figure 1 shows the data on irrigation quantity and crop evapotranspiration for the different treatments for two years. Total amount of irrigation water varied from 104 to $298 \mathrm{~mm}$ in both growing seasons. Totally 9 times irrigation applied in each years. Grapevine evapotranspiration (ET) varied from $229 \mathrm{~mm}$ in T-35 to $423 \mathrm{~mm}$ in $\mathrm{T}-\mathrm{F}$ in the 2016 and $222 \mathrm{~mm}$ in $\mathrm{T}-35$ to $416 \mathrm{~mm}$ in T-F in 2017 growing season. Our results are in agreement with [14].

Seasonal evapotranspiration (ET) increased with the increasing amount of irrigation. T-65 treatment resulted higher ET than the T-35 treatment in both years. Also 
Table 1. Effects of water deficit treatments on TSS, TA, pH, Anthocyanin content and Antioxidant Capacity in 2016 and 2017 seasons.

\begin{tabular}{ccccccc}
\hline & Treatments & TSS $(\%)$ & $\begin{array}{c}\text { TA } \\
\left(\mathbf{g ~ L}^{-1}\right)\end{array}$ & $\mathbf{p H}$ & $\begin{array}{c}\text { Total Anthocyanin } \\
(\text { Malvidin-3-glikozid) }\end{array}$ & $\left.\begin{array}{c}\text { Antioxidant } \\
\text { Capacity (EC }\end{array} \mathbf{5 0}\right)$ \\
\hline $\mathbf{2 0 1 6}$ & T-F & $16.70 \mathrm{~b}$ & 4.23 & $3.64 \mathrm{a}$ & $227.59 \mathrm{c}$ & 15.77 \\
& T-65 & $17.36 \mathrm{~b}$ & 4.14 & $3.56 \mathrm{~b}$ & $330.07 \mathrm{~b}$ & 13.07 \\
& T-35 & $18.76 \mathrm{a}$ & 4.04 & $3.46 \mathrm{c}$ & $595.35 \mathrm{a}$ & 12.80 \\
& $\mathbf{P}$ & $*$ & $\mathrm{~ns}$ & $*$ & $\mathrm{~ns}$ & $\mathrm{~ns}$ \\
\hline $\mathbf{2 0 1 7}$ & T-F & $14.76 \mathrm{~b}$ & $4.06 \mathrm{~b}$ & $3.8 \mathrm{~b}$ & $273.41 \mathrm{c}$ & $13.84 \mathrm{a}$ \\
& $\mathbf{T}-65$ & $15.10 \mathrm{~b}$ & $4.11 \mathrm{~b}$ & $3.89 \mathrm{a}$ & $584.35 \mathrm{~b}$ & $12.83 \mathrm{a}$ \\
& $\mathbf{T}-35$ & $15.70 \mathrm{a}$ & $4.29 \mathrm{a}$ & $3.84 \mathrm{~b}$ & $748.95 \mathrm{a}$ & $11.12 \mathrm{~b}$ \\
& $\mathbf{P}$ & $*$ & $*$ & $*$ & $*$ & $*$ \\
\hline
\end{tabular}

${ }^{*} p<0.05$, ns: non-significant.

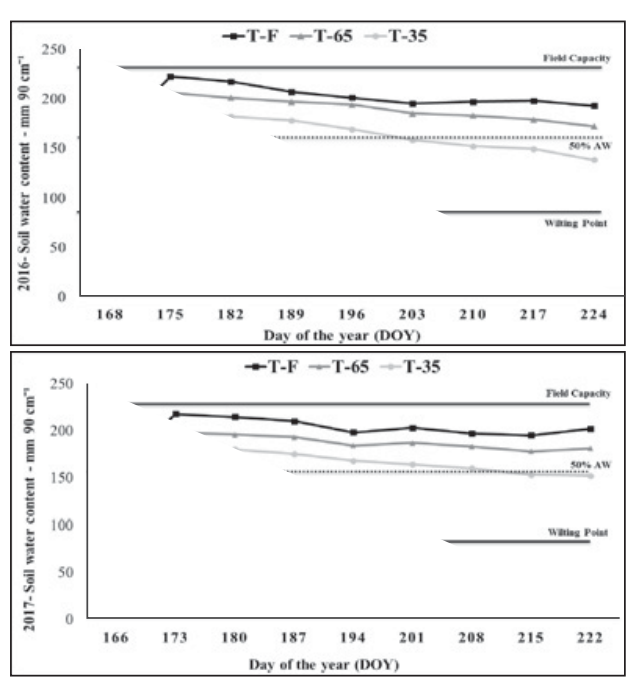

Figure 2. Soil water storage variations during 2016-2017 seasons for each treatments.

deficit irrigated vines can be reduced leaf area and stomatal conductance.

Therefore lower evapotranspiration values of deficit irrigated vines were observed compared to the full irrigated vines. These results are in agreement with the [15].

Soil water storage changes during the two growing seasons for each irrigation treatment are shown in Fig. 2.

Available soil water in T-F and T-65, treatment plots remained above $50 \%$ all over the growing seasons in both year. On the other hand in T-35 treatment in 2016, soil water content (SWC) remained below the $50 \%$ available water (AW) while plots gradually decreased in 2017. Deficit irrigation treatments reduced ET as compared to the T-F treatment [15-18].

Vine water status is a key factor under irrigated and non-irrigated conditions. Therefore many researchers recommended use of pressure chamber method as an ideal tool to measure vine water status [19-21]. Pressure chamber is widely used and constitute reference measurements of vine water status, between the low to high water stress levels. Generally grapevines without any water stress present $\Psi_{\mathrm{md}}$ values above to $-1.0 \mathrm{MPa}$, low water stress can be found at values above from -1.0 to $1.2 \mathrm{MPa}$, values from -1.2 to $-1.4 \mathrm{MPa}$ corresponds to moderate water stress, -1.4 to $-1.6 \mathrm{MPa}$ corresponds to high stress and values below the $-1.6 \mathrm{MPa}$ show severe water stress $[22,23]$.

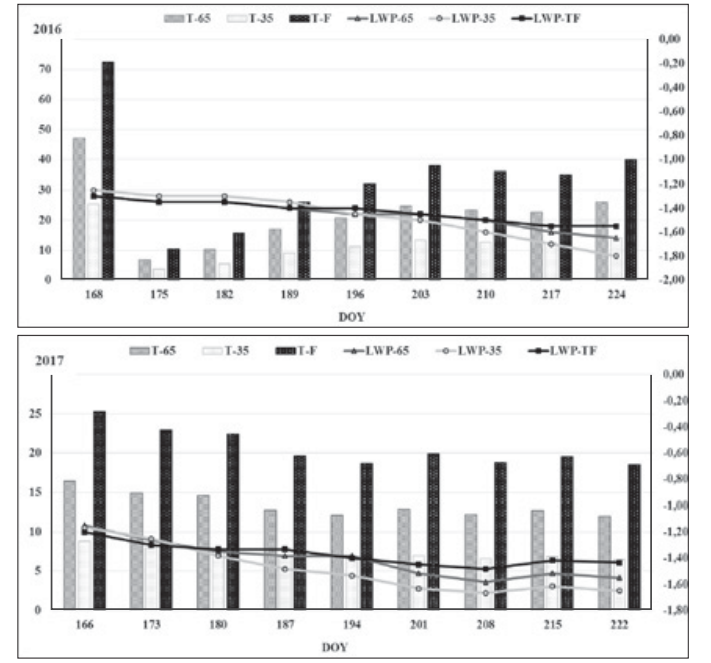

Figure 3. Relation between irrigation water quantity $(\mathrm{mm})$ and midday leaf water potential $\left(\Psi_{\mathrm{md}}\right)$.

The lower midday leaf water potential $\left(\Psi_{\mathrm{md}}\right)$ values were obtained by T-35 and T-65 treatments for all studied seasons (Fig. 3). On the contrary T-F treatments had highest $\Psi_{\mathrm{md}}$ values in both two years. Therefore it was found that $\Psi_{\text {md }}$ values were decreased with water restriction. These findings are in agreement with previous studies [20,24].

\subsection{Grape composition}

Application of different irrigation treatments have some changes on individual phenolics, total anthocyanin and antioxidant capacity values during two successive years. The soluble solids (TSS), titratable acidity (TA) and $\mathrm{pH}$ values were also determined. As shown in Table 1, TSS varied between 16.70 and 18.76 in 2016, 14.76 and 15.70 in 2017. Water deficit treatments had higher TSS values than the control (T-F) treatment. On the other hand TA ranged from 4.04 to 4.23 in 2016 and 4.06 to 4.29 in 2017. Also according to the OIV resolution VITI $1 / 2008$ [25], Fantasy seedless table grape variety are considered ripe since TSS values were equal to 16 brix or higher than 16 brix in the study. These findings are in agreement with [26].

As shown in Table 1, the total anthocyanin content ranged from 227.59 to 595.35 in 2016 and 273.41 to 748.95 in 2017. Also the effects of treatments on total 
anthocyanin content (Malvidin-3-glikozid) and antioxidant capacity $\left(\mathrm{EC}_{50}\right)$ were found statistically non-significant and significant in 2016 and 2017, respectively. However the highest anthocyanin content and antioxidant capacity values were observed in T-35 treatment during two growing seasons.

Also when the previous studies examined, it was found that total anthocyanin content and antioxidant activity were increased with water stress. It is well known fact that antioxidant enzymes such as SOD, CAT, POD and APX, increased in their activities under stress conditions. Therefore our findings were found similar with previous studies [27-29].

Besides changes in antioxidant capacity and total anthocyanin, individual phenolics changed in response to plant water status. On the other hand it was found in previous studies that the effects of water deficits on flavonol concentrations were smaller than on anthocyanins $[30,31]$. Phenolic contents of (Vitis vinifera L.) cv. Fantasy Seedless table grape variety were shown in Table 2.

Levels of gallic acid, catechin, cinnamic acid, trans-resveratrol, myricetin and quercetin hydrate were significantly influenced by the irrigation treatments in 2016. Whereas only levels of catechin were effected significantly in 2017. On the other hand Kaempferol, Oeinin chloride, Delphinidine chloride, Cyanidin chloride and Malvidine chloride were not detected in any grape samples during both years.

The most abundant phenolic substances detected were catechin as a flavonoid. The values varied from 9.15 to 22.11 in 2016 and 9.71 to 26.26 in 2017. Also [10] was found the most abundant phenolic compunds as catechin (17.82-33.59). Thirteen compunds were separated but caffeic acid and $p$-coumaric acid were not found in T-65 treatments during two years. The highest values of gallic acid, catechin, EGCG, ferulic acid, cinnamic acid, trans-resveratrol were obtained from T-65 treatment. These differences may be explained by water stress level. As shown in Table 2, some phenolic compounds were increased with mild stress (T-65) while decreased with severe stress (T-35). Therefore it can be seen that water stress period and doses are so important to accumulation of phenolics, synthesis of anthocyanins, antioxidant capacity and other quality attributes. According to the [32-34] expression of some of the genes responsible for anthocyanin and phenolics synthesis were shown to be increased by water deficits. And our findings would be an example on how mild stress affects berry composition positively. Secondary metabolites can be disrupted or enlarged by abiotic stress factors, especially drought. Therefore it was shown in grape that mild water stress is useful to develop organoleptic quality parameters of grapes. Also it was determined that changes in vine water status affect berry quality and berry compostion directly.

\section{Conclusion}

In general, extending these researches for the table grapes is necessary to understand how and what are the changes in terms of berry composition, fruit quality, anthocyanin synthesis, antioxidant capacity and individual phenolics. On the other hand these treatments should be applied in order to get the exportable quality for the table grapes 
and sustainable grape growing practices against to drought stress conditions as a result of climate change.

According to the findings it is obvious that different irrigation treatments effect anthocyanin accumulation, antioxidant capacity, individual phenolics, TSS, TA and $\mathrm{pH}$ values directly in this study. Specifically, T-65 (mild stress) treatment become prominent in terms of quality and berry composition attributes of (Vitis vinifera L.) cv. Fantasy Seedless table grape variety.

\section{References}

[1] G.V. Jones, M.A. White, O.R. Cooper, K. Storchmann, Climatic Change, 73, 319 (2005)

[2] A. Carbonneau, A. Deloire, B. Jaillard, Dunod, ParisFrance (2007), p. 442

[3] H. Ojeda, Cahier Thechnique Revue Freançaised' Oenologie (2008), p. 229

[4] P.R. Dry, B.R. Loveys, M.G. McCarthy, M. Stoll, Progrès Agricole et Viticole (France) (2001)

[5] C. Van Leeuwen, P. Friant, X. Chone, O. Tregoat, S. Koundouras, D. Dubourdieu, Amer. J. Enol. Viticul. 55, 207 (2004)

[6] C. Acevedo-Opazo, B. Tisseyre, S. Guillaume, H. Ojeda, Precision Agric. 9, 285 (2008)

[7] A. Teixeira, J. Eiras-Dias, S.D. Castellarin, H. Gerós, Int. J. Mol. Sci. 14, 18711 (2013)

[8] O. Soltekin, A. Candemir, A. Altindisli, Paper presented at: BIO Web of Conferences (EDP Sciences, 2016)

[9] L.E. Williams, P. Baeza, P. Vaughn, Irrigation Sci. 30, 201 (2011)

[10] G. Özkan, N.G. Baydar, Mediterranean Agric. Sci. 19, 229 (2006)

[11] C. Aubert, G. Chalot, Food Chem. 240, 524 (2018)

[12] M.M. Giusti, R.E. Wrolstad, Current Protocols in Food Analytical Chemistry (2001)

[13] W. Brand-Williams, M.E. Cuvelier, C.L.W.T. Berset, LWT-Food Sci. Technol. 28, 25 (1995)

[14] M. Sağlam, H. Işik, A. Gündüz, T. Uysal, Tekirdag Viniculture Research Institute Publications, Turkish (2003), p. 33

[15] Y.B. Çolak, A. Yazar, Scientia Horticulturae 224, 384 (2017)
[16] R.E. Smart, B.G. Coombe, Water Deficits and Plant Growth (New York-London, Academic Press, 1983), p. 137

[17] L.E. Williams, Practical Winery \& Vineyard 23, 42 (2001)

[18] C. Acevedo-Opazo, S. Ortega-Farias, S. Fuentes, Agric. Water Manage. 97, 956 (2010)

[19] H. Ojeda, C. Andary, E. Kraeva, A. Carbonneau, A. Deloire, Am. J. Enol. Vitic. 53, 261 (2002)

[20] J. Girona, M. Mata, J. Del Campo, A. Arbonés, E. Bartra, J. Marsal, Irrigation Sci. 24, 115 (2006)

[21] I. Sibille, H. Ojeda, J. Prieto, S. Maldonado, J.N. Lacapere, A. Carbonneau, In Proc. XVth Conf. GESCO (Croatia, 2007), p. 685

[22] A. Carbonneau, Traité d'irrigation, Aspects Qualitatifs (1998), p. 257

[23] A. Deloire, A. Carbonneau, Z. Wang, H. Ojeda, OENO One 38, 1 (2004)

[24] D.S. Intrigliolo, J.R. Castel, Agric. Water Manage. 96, 282 (2009)

[25] OIV Standard on Minimum Maturity Requirements for Table Grapes. Paris: Organisation Internationale de la Vigne et du Vin (2008)

[26] C. Aubert, G. Chalot, Food Chem. 240, 524 (2018)

[27] M. Ozden, U. Demirel, A. Kahraman, Scientia Horticulturae 119, 163 (2009)

[28] M.M. Chaves, O. Zarrouk, R. Francisco, J.M. Costa, T. Santos, A.P. Regalado, M.L. Rodrigues, C.M. Lopes, Ann. Bot. 105, 661 (2010)

[29] J.F. Meng, T.F. Xu, Z.Z. Wang, Y.L. Fang, Z.M. Xi, Z.W. Zhang, J. Pineal Res. 57, 200 (2014)

[30] J. Grimplet, L.G. Deluc, R.L. Tillett, M.D. Wheatley, K.A. Schlauch, G.R. Cramer, J.C. Cushman, BMC Genom. 8, 1 (2007)

[31] M. Niculcea, L. Martínez Lapuente, Z. Guadalupe, M. Sánchez-Díaz, B. Ayestarán, M.C. Antolín Bellver, Vitis - J. Grapevine Res. 54, 9 (2015)

[32] S.D. Castellarin, M.A. Matthews, G. Di Gaspero, G.A. Gambetta, Planta 227, 101 (2007)

[33] L.G. Deluc, D.R. Quilici, A. Decendit, J. Grimplet, M.D. Wheatley, K.A. Schlauch, G.R. Cramer, BMC Genomics 10, 212 (2009)

[34] L.G. Santesteban, C. Miranda, J.B. Royo, Agric. Water Manage. 98, 1171 (2011) 